\title{
LA SOCIEDAD DE LA INFORMACIÓN Y EL DERECHO DE LOS MENORES. CONTENIDOS E INDEFENSIÓN EN RELACIÓN CON EUROPA
}

\section{THE INFORMATION SOCIETY AND THE RIGHT OF MINORS. CONTENTS AND HELPLESSNESS IN RELATION TO EUROPE}

Maribel Martínez Eder: Portavoz de FIATYR (Federación Ibérica de Telespectadores y Radioyentes) mm.eder@asociacionplazadelcastillo.org

\section{CURRÍCULUM VITAE}

Fundadora y presidenta de la Asociación Plaza del Castillo ATR Navarra de Usuarios de Medios de Comunicación, integrante de FIATYR (Federación Ibérica de Asociaciones de Telespectadores y Radioyentes). Fue miembro del Consejo Asesor de RTVE en Navarra.

\section{RESUMEN}

La vida real tiene muy poco que ver, o más bien nada, con la realidad virtual que se crea en los medios de comunicación, en especial en la televisión, en horario de prime time o de máxima audiencia. El problema es que terminan influyendo en el público infantil y adolescente. Y como es muy barata de realizar y genera audiencia acrítica, se sigue produciendo ese tipo de televisión. 


\title{
PALABRAS CLAVE
}

Televisión - Niño - Derechos - Realidad Virtual

\begin{abstract}
Real life has little to do, or rather nothing, virtual reality is created in the media, especially television, in prime time and prime time. The problem is that end up influencing the child and adolescent audiences. And because it's very cheap to make and generates uncritical audience, is still produced such television.
\end{abstract}

\section{KEY WORDS}

Television - Children - Rights - Virtual Reality

\section{TEXTO}

Pensando en la relación Medios de Comunicación y derecho de los menores en España, y su equivalente en Europa, no se trata en absoluto de mostrar una situación catastrófica de la sociedad, sino todo lo contrario; por fortuna la vida real tiene muy poco que ver con la realidad virtual falsa y prefabricada que frecuentemente, presentan algunos medios de comunicación, en especial la televisión, en horas de máxima audiencia. 
La sociedad española, por tanto, con enormes sombras pero también rutilantes luces, es, en general, infinitamente más diversa, plural, culta, y civilizada de lo que se trasmite a través de los medios, muy en especial, recalco, de la televisión.

Cosa bien diferente es la influencia a la que están sometidos sobre todo niños y adolescentes a contenidos violentos desde el cine, los telefilmes, videojuegos, etc. Desde hace decenios venimos denunciando que tales contenidos generan violencia en la vida privada, aulas, calles, etc. Nos gustaría equivocarnos, pero desde luego, nos quedamos cortos para lo que vemos y por desgracia, veremos.

A continuación las conclusiones a las que llegamos después de muchos años de estudio sistemático.

-La televisión y la contracultura que trasmiten, no siempre reflejan la sociedad a la que sirven, sino que la influyen.

-El responsable de lo emitido es siempre el emisor. Tiene todo el poder para programar, emitir, publicitar, crear hábitos.

-Lo más perverso de la televisión-basura es decir que la pedimos. Por más que suele estar muy publicitada y ubicada en horarios de máxima audiencia, lo más visto viene siendo en los últimos años: deporte; informativos; series y películas. Si se sigue produciendo y emitiendo es principalmente por dos razones: Es muy barata de realizar, y crea una audiencia acrítica.

Espero que éstos razonamientos sirvan para entender mejor los aspectos que pretendo poner sobre el papel. 
Contenidos e indefensión

Cuando un niño en España se pone delante del televisor, por ejemplo a la vuelta del colegio, por supuesto en horarios de protección* e incluso en los superprotegidos, hallará, con toda probabilidad, contenidos inadecuados e indeseables, televisión basura y ni la mínima referencia cultural.

Además, salvo excepción, no encontrará ninguna programación dedicada precisamente a la infancia, ámbito dejado de la mano de Dios por las productoras y responsables de contenidos desde tiempo inmemorial. Tal circunstancia no se puede achacar a que no sean comerciales. Los lunnis por ejemplo, es un producto muy rentable, muy bien aceptado y en torno al cual ha florecido un dinámico "marketing" que, por fuerza, debe satisfacer a los responsables del Ente de RTVE. Pues bien: tardaron años en comprender las razones que les presentábamos para cambiar la política audiovisual en ese terreno.

La explicación de ésta "política", la única explicación que se alcanza, es que se trata de ir "preparando" a nuevas generaciones de consumidores no sólo en el relativismo más absoluto (valga la expresión), sino en fidelizar, aficionar al cotilleo, normalizar el acoso a la intimidad y al uso de cámaras ocultas, estimular la afloración de las más bajas pasiones humanas, el consumismo descarnado, el materialismo (en todas sus expresiones), Repito, sin la mínima referencia cultural en horas de máxima audiencia, y no hablemos de referencias espirituales y/o trascendentes.

Por supuesto la dosis de violencia diaria está asegurada (horas y horas dedicadas al contenido creado a partir de la crónica negra, tanto en la televisión de titularidad pública como privada); teniendo presente que una nación de 45 millones de habitantes genera una crónica negra diaria, a veces muy sórdida, los contenidos los 
tienen asegurados de por vida, con la consiguiente banalización. Cuando en los sucesos hay niños de por medio, o maltrato doméstico (últimamente maltrato a animales), mejor que mejor.

Hay otros aspectos inconcebibles asimismo en otros países y que ocurren en España con total normalidad y que por cierto, no suelen ser objeto de debate ni en prensa, ni en radio ni por supuesto en televisión.

Siendo en general en nuestro país los hoteles excelentes, el primer servicio suele ser el de la pornografía; muchos clientes extranjeros se escandalizan y no desean dejar a sus niños solos por la noche, por ejemplo. Me refiero a avances de películas en abierto, etc.

Prensa pretendidamente muy seria que dedica páginas y páginas a publicitar la prostitución (la mayor esclavitud de nuestro tiempo), de la forma más explícita que nos podamos imaginar.

La revista "!qué me dices!" regalada los sábados con el periódico La razón; publicidad: "relato erótico interactivo", "Kamasutra" con dibujos animados de menores", etc. Es muy importante consignar que es regalada, que llega a tu propia casa $\mathrm{y}$, por supuesto, se pone al alcance de los niños (los padres y tutores generalmente no lo saben), sin haberla ido a comprar, digo la pornografía, expresamente.

Aspectos que considero esenciales y muy negativos en relación con los distintos países de nuestra área cultura y geográfica: 
-La indefensión, en general, de los usuarios españoles ante los medios de comunicación en especial de la televisión, en el caso de los niños.

-La práctica ausencia de programación dedicada a la infancia.

-Contenidos fraudulentos y pornografía dura en abierto (en torno a 1.000 emisoras en toda la geografía española sin licencia), es decir ilegales, en el año 2004.

-El incumplimiento de todo código de autorregulación, demostrado en los distintos informes Villanueva.

-La ausencia de una autoridad audiovisual que vigile el cumplimiento de la normativa vigente.

Por supuesto que en el resto de Europa sería impensable una situación semejante por la razón definitiva de que existe autoridad audiovisual en todos los países de nuestra área cultural y geográfica y aún en los en vías de desarrollo.

Considerando además, la extraordinaria relación que las nuevas generaciones tienen con las "pantallas": videojuegos, televisión, internet; según publica Diario de Navarra de 4 de Noviembre de 2007, estudios muy serios afirman que, por ejemplo, el 70\% de los niños entre 10 y 14 años, navega solo por la red y sólo un 10\% tiene filtros de contenido.

¿Han escuchado a algún político sea de derechas, de izquierdas o de centro, en campaña o en pre-campaña aludir a alguno de éstos temas? Yo tampoco.

Pamplona-Madrid Febrero de 2008. 